\title{
Application of Simplex Lattice Design in Maize Fodder Production
}

\author{
Joseph Kipyegon.Cheruiyot ${ }^{1}$, Joseph K. Arap Koske ${ }^{2}$ and John Mutiso ${ }^{3}$ \\ Department of Statistics and Computer Science, \\ School of Biological and Physical science, Moi University, Eldoret Kenya \\ Correspondent Email: jcheruiyot34@gmail.com
}

\begin{abstract}
This study involved mixture experiment using simplex lattice design approach in cultivation of Maize crop with the view of optimizing the fertilizer components (dependent variables) on the output parameter (maize fodder). The objective of this study was to evaluate optimal sets of mixture of fertilizer components that could maximize the response variables of interest. Di-Ammonium Phosphate (DAP), Poultry manure, Sheep manure, and Farmyard manure components mixed in various proportions in accordance with simplex lattice design were applied in planting hybrid maize seeds. With the application of the special cubic statistical model formulated, it was found that farmyard manure and poultry manure produced the optimal fertilizer condition. However, the this study further provided specific optimal fertilizer blend for maize fodder production as 8.0 tons ha ${ }^{-1}$ of farmyard manure mixed with 1.212 tons ha ${ }^{-1}$ of poultry manure. Under these conditions, a maximum outputs 42 tons ha ${ }^{-1}$ of maize fodder were realized. The study concluded that the formulation of statistical model for crop production could be useful for prediction and evaluation of the effects of experimental factors.
\end{abstract}

KEY WORDS: Maize fodder; Fertilizer components; Model; Mixture experiment; Simplex Lattice Design;

DOI: 10.7176/MTM/9-7-05

Publication date: July $31^{\text {st }} 2019$

\subsection{INTRODUCTION}

Response surface methodology (RSM), is a collection of mathematical and statistical techniques that are useful for the modeling and analysis of problems in which a response of interest is influenced by several variables and the objective is to optimize this response (Montgomery 2000).

Mixture experiments are commonly encountered in several fields, including the food, chemical, pharmaceutical, engineering and consumer products among many others. For mixture experiments, the design factors are the proportions of the components under study that sum to a constant, and response variable depends on these proportions. A number of mixtures experimental designs have been formulated but the most commonly applied is simplex-lattice design. It takes the shape of a triangle with the pure blends being located at the vertices of the triangle for a case of a three-component mixture. Interior points give blends of all the components while data collected at the midpoint of the edges of the triangular surface gives the response for the binary blends. However, for a four-component mixture it takes the form of a tetrahedron.

Among other factors, the mixtures experiments provide information about one or more product properties, which is of interest to the manufacturer or experimenter who is responsible for mixing the ingredients. Another reason for mixing together ingredients in blending experiments is to see if there exist blends of two or more ingredients that produce more desirable product properties than is obtainable with the single ingredients individually.

In dealing with mixture experiments, one studies the response surface of a given response variable, y as a function of $\mathrm{q}$ factors $(\mathrm{q} \geq 3)$. A proportion, $\mathrm{x}_{\mathrm{i}}$, in the mixture satisfying the following restrictions, represents all the $\mathrm{q}$ factors (ingredients)

$$
\sum_{i=1}^{\mathrm{q}} \mathrm{x}_{\mathrm{i}}=1 \text { and } 0 \leq \mathrm{x}_{\mathrm{i}} \leq 1 \text {, where } \mathrm{i}=1, \ldots \mathrm{q} \text {. }
$$

The book of (Khuri and Cornell 1987) gives a well elaborate account of work done on experiments with mixtures Boateng et al.(2006), investigated the effect of Poultry manure on the growth of maize crop and found that poultry manure significantly increased the grain yield. The research recommended that an application of over 2.5tons/ hectare guarantee a good yield. Further, Shiyam et al.(March 2017), concluded that growth and grain yield of maize were improved by poultry manure application. Further, a research done in 2014 in University of Sagodha Punjab India, concluded that the applications of organic matter with inorganic fertilizers were having favorable effect on the fresh plant weight of maize crop. Hence, the researcher Awais Shakoor et al. (2015), asserted that the combination of organic and Inorganic fertilizers increase maize production. 
From the available literature on fertilizers and Manure, it is observed that most research work investigated the effects of single manure component on maize crop. Therefore, the gap can be seen to exist mainly on binary blends either between organic matter and inorganic or both organic components. Furthermore, where the synergies of such components have been investigated, the actual quantities and proportion that constitute the optimal set of conditions for maximum crop production have not been documented. This study therefore explores to fill such a gap.

\subsection{MATERIAL AND METHODS}

Attainment of the set objectives becomes the major consideration in the selection of the design of the experiment. Though, design with small number of runs, if it provides enough information on the coefficients are cost effective as compared to designs with large number of runs.

\subsection{Field experiment}

The Simplex lattice design comprising of four factors third degree polynomial $\{4,3\}$ was selected for used. The problem was to investigate the effects of fertilizer components on the maize fodder production by varying the proportions of the mixture simultaneously and maintaining the amount constant (Scheffe' 1958). The coded variables $\mathrm{x}_{1}, \mathrm{x}_{2}, \mathrm{x}_{3}$ and $\mathrm{x}_{4}$ were adopted to represent farmyard manure, Di-Ammonium Phosphate- DAP, Sheep manure and Poultry manure respectively. Using a $\{4,3\}$ design, 20 possible combination (runs) were formulated. From the agronomist analysis of soil nutrients, the amounts of each fertilizer recommended for use in cultivation of maize was estimated as provided in table 1.

Table 1: Amount of fertilizer applied per hectare.

\begin{tabular}{lllll}
\hline & \multicolumn{4}{c}{ Actual values (Tonnes per hectare) } \\
\cline { 2 - 5 } Coded levels & $\mathrm{x}_{1}$ & $\mathrm{x}_{2}$ & $\mathrm{x}_{3}$ & $\mathrm{X}_{4}$ \\
$\mathbf{1}$ & 20 & 10 & 0.312 & 2.02 \\
\hline
\end{tabular}

Table 2: Design matrix for coded and actual fertilizer application.

\begin{tabular}{lllllllll}
\hline & \multicolumn{4}{c}{ Coded values } & \multicolumn{5}{c}{ Actual values in Tons /Ha } \\
\hline Runs & $\mathrm{x}_{1}$ & $\mathrm{x}_{2}$ & $\mathrm{x}_{3}$ & $\mathrm{x}_{4}$ & $\mathrm{x}_{1}$ & $\mathrm{x}_{2}$ & $\mathrm{x}_{3}$ & $\mathrm{x}_{4}$ \\
$\mathbf{1}$ & 1 & 0 & 0 & 0 & 20 & 0 & 0 & 0 \\
$\mathbf{2}$ & 0 & 1 & 0 & 0 & 0 & 0.312 & 0 & 0 \\
$\mathbf{3}$ & 0 & 0 & 1 & 0 & 0 & 0 & 10 & 0 \\
$\mathbf{4}$ & 0 & 0 & 0 & 1 & 0 & 0 & 0 & 2.02 \\
$\mathbf{5}$ & 0.66666 & 0.33333 & 0 & 0 & 13.33 & 0.104 & 0 & 0 \\
$\mathbf{6}$ & 0.66666 & 0 & 0.33333 & 0 & 13.33 & 0 & 3.33 & 0 \\
$\mathbf{7}$ & 0.66666 & 0 & 0 & 0.33333 & 13.33 & 0 & 0 & 0.673 \\
$\mathbf{8}$ & 0.33333 & 0.66666 & 0 & 0 & 6.67 & 0.208 & 0 & 0 \\
$\mathbf{9}$ & 0.33333 & 0.33333 & 0.33333 & 0 & 6.67 & 0.104 & 3.33 & 0 \\
$\mathbf{1 0}$ & 0.33333 & 0.33333 & 0 & 0.33333 & 6.67 & 0.104 & 0 & 0.673 \\
$\mathbf{1 1}$ & 0.33333 & 0 & 0.66666 & 0 & 6.67 & 0 & 6.67 & 0 \\
$\mathbf{1 2}$ & 0.33333 & 0 & 0.33333 & 0.33333 & 6.67 & 0 & 3.33 & 10.673 \\
$\mathbf{1 3}$ & 0.33333 & 0 & 0 & 0.66666 & 6.67 & 0 & 0 & 1.347 \\
$\mathbf{1 4}$ & 0 & 0.66666 & 0.33333 & 0 & 0 & 0.208 & 3.33 & 0 \\
$\mathbf{1 5}$ & 0 & 0.66666 & 0 & 0.33333 & 0 & 0.208 & 0 & 0.673 \\
$\mathbf{1 6}$ & 0 & 0.33333 & 0.66666 & 0 & 0 & 0.104 & 6.67 & 0 \\
$\mathbf{1 7}$ & 0 & 0.33333 & 0.33333 & 0.33333 & 0 & 0.104 & 3.33 & 0.673 \\
$\mathbf{1 8}$ & 0 & 0.33333 & 0 & 0.66666 & 0 & 0.104 & 0 & 1.347 \\
$\mathbf{1 9}$ & 0 & 0 & 0.66666 & 0.33333 & 0 & 0 & 6.67 & 0.673 \\
$\mathbf{2 0}$ & 0 & 0 & 0.33333 & 0.66666 & 0 & 0 & 3.33 & 1.347 \\
\hline
\end{tabular}


The order of the fertilizer component as selected randomly in the actual field cultivation was as follows: $\mathrm{x}_{1}$ Farmyard manure, $\mathrm{x}_{2}$ - Di - Ammonium Phosphate, $\mathrm{x}_{3}$-Sheep manure and $\mathrm{x}_{4}$-Poultry manure.

\subsection{Statistical model}

According to Cornell (1990), the measured response is assumed to depend only on the proportions of the ingredients present in the mixture but not on the amount of the mixture. Hence, a third degree regression model expressing the response variable maize fodder as a function of the input variables; farmyard manure, DAP, sheep manure and poultry manure was derived. In the model, $\mathrm{x}_{1}, \mathrm{x}_{2}, \mathrm{x}_{3}$ and $\mathrm{x}_{4}$ are signed to the four fertilizer input components. A special cubic model can be expressed as;

$$
\mathrm{y}=\sum_{\mathrm{i}=1}^{4} \beta_{\mathrm{i}} \mathrm{x}_{\mathrm{i}}+\sum_{\substack{\mathrm{j} \\ \mathrm{i}<\mathrm{j}}}^{4} \sum_{\mathrm{i}}^{4} \beta_{\mathrm{ij}} \mathrm{x}_{\mathrm{i}} \mathrm{x}_{\mathrm{j}}+\sum_{\substack{\mathrm{k} \\ \mathrm{i}<\mathrm{j}<\mathrm{k}}}^{4} \sum_{\mathrm{j}}^{4} \sum_{\mathrm{i}}^{4} \beta_{\mathrm{ijk}} \mathrm{x}_{\mathrm{i}} \mathrm{x}_{\mathrm{j}} \mathrm{x}_{\mathrm{k}}
$$

Where, $\beta_{\mathrm{i}}, \beta_{\mathrm{ij}}$ and $\beta_{\mathrm{ijk}}$ are parameters or coefficients of interest. The model as shown above is preferred over the lower-degree models because the terms in the special cubic model not only provide a measure of each of pure blend, but provide measures of binary blends and a measure of the three-component blend as well.

\subsection{Model analysis}

The tools used to test the appropriateness of the model for statistical analysis were ANOVA test and graphs of the line of best fit. ANOVA involved the sum of squares and F- statistics to find out the importance of the parameters. However, in testing fitness of the model, a plot of predicted values against the actual experimental values was used. The other measure computed was the adjusted coefficient of determination (adjusted R square). This explains the amount of variation by the model. The computational formula is as follows;

$$
\mathrm{R}_{\mathrm{A}}^{2}=1-\frac{\mathrm{SSE} /(\mathrm{N}-\mathrm{p})}{\mathrm{SST} /(\mathrm{N}-1)}
$$

\subsection{Mixture experiment}

The data was obtained from the experiment carried out at University of Kabianga research and teaching farm. The necessary land preparation was done on the piece of land selected for study. It was then subdivided into 20 plots, each measuring $2 \mathrm{~m}$ by $2.5 \mathrm{~m}$, and each of the plots having three rows of 10 stands (holes).

The relevant laboratory tests to ascertaining the manure ingredients and the soil nutrient content were carried out. Therefore, estimation of fertilizer application per hectare was arrived at based on the outcome of soil and manure analyses. Having done the necessary agronomic practices certified maize seeds (Hybrid628) were planted. The seeds were planted at a spacing of $0.75 \mathrm{M}$ inter-row and $0.25 \mathrm{M}$ intra-row. After emergence, thinned was carried out to one plant per stand resulting in a plant population of 53,750 per hectare. Timely weeding was done with only one repeat for entire season. 


\subsection{RESULTS AND DISCUSSION}

\subsection{Experimental values.}

Table3: Design matrix of independent and dependent variables together with the corresponding predicted values.

\begin{tabular}{lllllll}
\hline \multicolumn{7}{c}{ Coded Values } \\
\hline Runs & X1 & X2 & X3 & X4 & EXP Y & PRED Y \\
$\mathbf{1}$ & 1 & 0 & 0 & 0 & 9.33 & 9.49 \\
$\mathbf{2}$ & 0 & 1 & 0 & 0 & 10.45 & 10.19 \\
$\mathbf{3}$ & 0 & 0 & 1 & 0 & 10.32 & 10.40 \\
$\mathbf{4}$ & 0 & 0 & 0 & 1 & 10.9 & 10.92 \\
$\mathbf{5}$ & 0.66666 & 0.33333 & 0 & 0 & 11.82 & 11.52 \\
$\mathbf{6}$ & 0.66666 & 0 & 0.33333 & 0 & 11.18 & 11.20 \\
$\mathbf{7}$ & 0.66666 & 0 & 0 & 0.33333 & 12.24 & 12.04 \\
$\mathbf{8}$ & 0.33333 & 0.66666 & 0 & 0 & 11.45 & 11.67 \\
$\mathbf{9}$ & 0.33333 & 0.33333 & 0.33333 & 0 & 11.17 & 11.17 \\
$\mathbf{1 0}$ & 0.33333 & 0.33333 & 0 & 0.33333 & 10.01 & 10.01 \\
$\mathbf{1 1}$ & 0.33333 & 0 & 0.66666 & 0 & 11.52 & 11.50 \\
$\mathbf{1 2}$ & 0.33333 & 0 & 0.33333 & 0.33333 & 12.11 & 12.11 \\
$\mathbf{1 3}$ & 0.33333 & 0 & 0 & 0.66666 & 12.32 & 12.52 \\
$\mathbf{1 4}$ & 0 & 0.66666 & 0.33333 & 0 & 11.52 & 11.67 \\
$\mathbf{1 5}$ & 0 & 0.66666 & 0 & 0.33333 & 11.71 & 12.04 \\
$\mathbf{1 6}$ & 0 & 0.33333 & 0.66666 & 0 & 11.89 & 11.74 \\
$\mathbf{1 7}$ & 0 & 0.33333 & 0.33333 & 0.33333 & 11.04 & 6.13 \\
$\mathbf{1 8}$ & 0 & 0.33333 & 0 & 0.66666 & 12.61 & 12.28 \\
$\mathbf{1 9}$ & 0 & 0 & 0.66666 & 0.33333 & 12.25 & 12.16 \\
$\mathbf{2 0}$ & 0 & 0 & 0.33333 & 0.66666 & 12.25 & 12.34 \\
\hline
\end{tabular}

Table 3 shows that for all the plots, the coded variable $\mathrm{x}_{\mathrm{i}}$, was provided as $0 \leq x_{i} \leq 1$ and $\sum_{i} x_{i}=1$ and the dependent variables that is, the response maize Fodder $(\mathrm{Y})$ were given in Kilograms corrected to two decimal places. To determine the effects of fertilizer components on the maize fodder ANOVA analysis was used and considered significant at 5\% confident interval. Data was analyzed using statistical package design expert version 11 with the view of obtaining regression model.

\subsection{Model summary statistics}

The study sought to determine the most suitable statistical model that best fit the maize fodder data obtained from the experiment. The summary of the results found were as displayed in table 4 below. 
Table 4. Model summary statistics for maize fodder

\begin{tabular}{llllll}
\hline Source & Std. Dev. & $\mathrm{R}^{2}$ & Adjusted R & PRESS & \\
& & & & & \\
\hline Linear & 0.8651 & 0.1607 & 0.0033 & 42.06 & \\
Quadratic & 0.9058 & 0.4248 & 0.0928 & $*$ & Suggested \\
Special Cubic & $\mathbf{0 . 3 2 5 9}$ & $\mathbf{0 . 9 5 5 3}$ & $\mathbf{0 . 8 5 8 5}$ & $*$ & Aliased \\
Special Quartic & 0.3259 & 0.9553 & 0.8585 & $*$ & \\
\hline
\end{tabular}

Table 4 provides model summary statistic and the focus was on the model maximizing the adjusted $\mathrm{R}^{2}$. The value found for special cubic model was 0.8565 . This implies that the model explains about $85.7 \%$ of the variability in the response variable. Note that adjusted R-squared is mostly used to summarize the fit since it accounts for the number of variables in the model. Therefore, special cubic model took preference over the other models in this study.

\subsection{Model formulation.}

Next was to formulate a third order statistical model in according to the simplex lattice coded variables. Hence, the evaluated values of the parameter estimates were as tabulated below in table 5 .

Table 5: Coefficients in terms of coded factors on maize yield

\begin{tabular}{llll}
\hline Variable & Estimate & Std. Error & P-value \\
\hline $\mathbf{X}_{\mathbf{1}}$ & 9.49 & 0.3028 & 0.0204 \\
$\mathbf{X}_{\mathbf{2}}$ & 10.19 & 0.3028 & 0.0204 \\
$\mathbf{X}_{\mathbf{3}}$ & 10.40 & 0.3028 & 0.0204 \\
$\mathbf{X}_{\mathbf{4}}$ & 10.92 & 0.3028 & 0.0204 \\
$\mathbf{X}_{\mathbf{1}} \mathbf{X}_{\mathbf{2}}$ & 8.08 & 1.43 & 0.0013 \\
$\mathbf{X}_{\mathbf{1}} \mathbf{X}_{\mathbf{3}}$ & 6.31 & 1.43 & 0.0045 \\
$\mathbf{X}_{\mathbf{1}} \mathbf{X}_{\mathbf{4}}$ & 9.35 & 1.43 & 0.0006 \\
$\mathbf{X}_{\mathbf{2}} \mathbf{X}_{\mathbf{3}}$ & 6.34 & 1.43 & 0.0045 \\
$\mathbf{X}_{\mathbf{2}} \mathbf{X}_{\mathbf{4}}$ & 7.23 & 1.43 & 0.0023 \\
$\mathbf{X}_{3} \mathbf{X}_{\mathbf{4}}$ & 7.16 & 1.43 & 0.0025 \\
$\mathbf{X}_{\mathbf{1}} \mathbf{X}_{\mathbf{2}} \mathbf{X}_{\mathbf{3}}$ & -31.34 & 10.61 & 0.0255 \\
$\mathbf{X}_{\mathbf{1}} \mathbf{X}_{\mathbf{2}} \mathbf{X}_{\mathbf{4}}$ & -79.06 & 10.61 & 0.0003 \\
$\mathbf{X}_{\mathbf{1}} \mathbf{X}_{\mathbf{3}} \mathbf{X}_{\mathbf{4}}$ & -18.76 & 10.61 & 0.1274 \\
$\mathbf{X}_{\mathbf{2}} \mathbf{X}_{\mathbf{3}} \mathbf{X}_{\mathbf{4}}$ & -47.68 & 10.61 & 0.0041 \\
\hline
\end{tabular}

The effects of the variables as linear, quadratic or tertiary interaction on the response variable were tested for significance. The study found that all linear components farmyard manure $\left(\mathrm{X}_{1}\right)$, DAP $\left(\mathrm{X}_{2}\right)$, Sheep manure $\left(\mathrm{X}_{3}\right)$ and Poultry manure $\left(\mathrm{X}_{4}\right)$ had significant effect on the maize fodder with a common p-value equivalent to 0.0204 , which is less than 0.05 . This implies that for a unit increase in farmyard manure holding other factors constant; 
translate to an increase in maize fodder by a factor 9.49. Similarly, for a unit increase for each of the other components (DAP, sheep manure and poultry manure) holding other factors constant in turns translates to an increase by a factor $10.17,10.40$ and 10.92 respectively.

From the estimates, the poultry manure stands as superior manure followed by sheep. However, the study found that the effects on maize fodder from the mixture for each of the six binary components, to be statistically significant since all indicated a $\mathrm{P}$ - value less than 0.05. Moreover, their estimate values were all positive implying that the two components interaction effects are synergetic in nature.

The model obtained for the maize fodder as a function of the coded variables presented in table 5 of coefficients is as follows:

$\mathrm{y}=9.49045 \mathrm{x}_{1}+10.19 \mathrm{x}_{2}+10.40409 \mathrm{x}_{3}+10.91545 \mathrm{x}_{4}+8.07648 \mathrm{x}_{1} \mathrm{x}_{2}+6.31227 \mathrm{x}_{1} \mathrm{x}_{3}+9.3467 \mathrm{x}_{1} \mathrm{x}_{4}$ $6.3358 x_{2} x_{3}+7.23273 x_{2} x_{4}-8.33472 x_{3} x_{4}-31.34455 x_{1} x_{2} x_{3}-79.06091 x_{1} x_{2} x_{4}-18.765 x_{1} x_{3} x_{4}$ $-47.67955 x_{2} x_{3} x_{4}$

Where $\mathrm{y}$ is the predicted response for Maize fodder and $\mathrm{x}_{\mathrm{i}}(\mathrm{i}=1,2,3,4)$ represent the control factors in the experimental data ( $1=$ farmyard manure, $2=$ DAP. $3=$ sheep manure, $4=$ poultry manure).

\subsection{Analysis of variance (ANOVA)}

In order to check the model's adequacy for the response variable; maize fodder, for the experimental data at $95 \%$ confidence level, Analysis of variance (ANOVA) was used.

Table 6. ANOVA table for the effect of fertilizers on maize fodder.

\begin{tabular}{|c|c|c|c|c|c|c|}
\hline Source & DF & SS & MSS & F-value & F-Critical & P-value \\
\hline Model & 13 & 13.64 & 1.05 & 9.88 & 2.92 & 0.0051 \\
\hline Linear Mixture & 3 & 2.30 & 0.7671 & 7.23 & 8.94 & 0.0204 \\
\hline $\mathbf{X}_{1} \mathbf{X}_{2}$ & 1 & 3.37 & 3.37 & 31.79 & 5.99 & 0.0013 \\
\hline $\mathbf{X}_{1} \mathbf{X}_{3}$ & 1 & 2.06 & 2.06 & 19.42 & 5.99 & 0.0045 \\
\hline $\mathbf{X}_{1} \mathbf{X}_{4}$ & 1 & 4.52 & 4.52 & 42.57 & 5.99 & 0.0006 \\
\hline $\mathbf{X}_{2} \mathbf{X}_{3}$ & 1 & 2.08 & 2.08 & 19.56 & 5.99 & 0.0045 \\
\hline $\mathbf{X}_{2} \mathbf{X}_{4}$ & 1 & 2.71 & 2.71 & 25.49 & 5.99 & 0.0023 \\
\hline $\mathbf{X}_{3} \mathbf{X}_{4}$ & 1 & 2.65 & 2.65 & 24.96 & 5.99 & 0.0025 \\
\hline $\mathbf{X}_{1} \mathbf{X}_{2} \mathbf{X}_{3}$ & 1 & 0.9266 & 0.9266 & 8.73 & 5.99 & 0.0255 \\
\hline $\mathbf{X}_{1} \mathbf{X}_{2} \mathbf{X}_{4}$ & 1 & 5.89 & 5.89 & 55.53 & 5.99 & 0.0003 \\
\hline $\mathbf{X}_{1} \mathbf{X}_{3} \mathbf{X}_{4}$ & 1 & 0.3321 & 0.3321 & 3.13 & 5.99 & 0.1274 \\
\hline $\mathbf{X}_{2} \mathbf{X}_{3} \mathbf{X}_{4}$ & 1 & 2.14 & 2.14 & 20.20 & 5.99 & 0.0041 \\
\hline Residual & 6 & 0.6369 & 0.1062 & & & \\
\hline Total & 19 & 14.28 & & & & \\
\hline
\end{tabular}


The model's F-value of 9.88 implies that the model is significant based on F-test at $95 \%$ confidence interval, since the F-value of 9.88 is higher than F-critical=2.92. Furthermore, the model P-values=0.005 with in the of acceptance level of less than 0.05. This clearly indicates that model satisfies the model adequacy condition. In addition, the linear components were also statistically significant with a P-value of $0.0204<5$ percentage significant levels.

\subsection{Test for normality}

The assessment of the normality of data is a requirement for many statistical tests because normal data is an underlying assumption in parametric testing. Hence, figure 1 below show the normal plot of residuals.

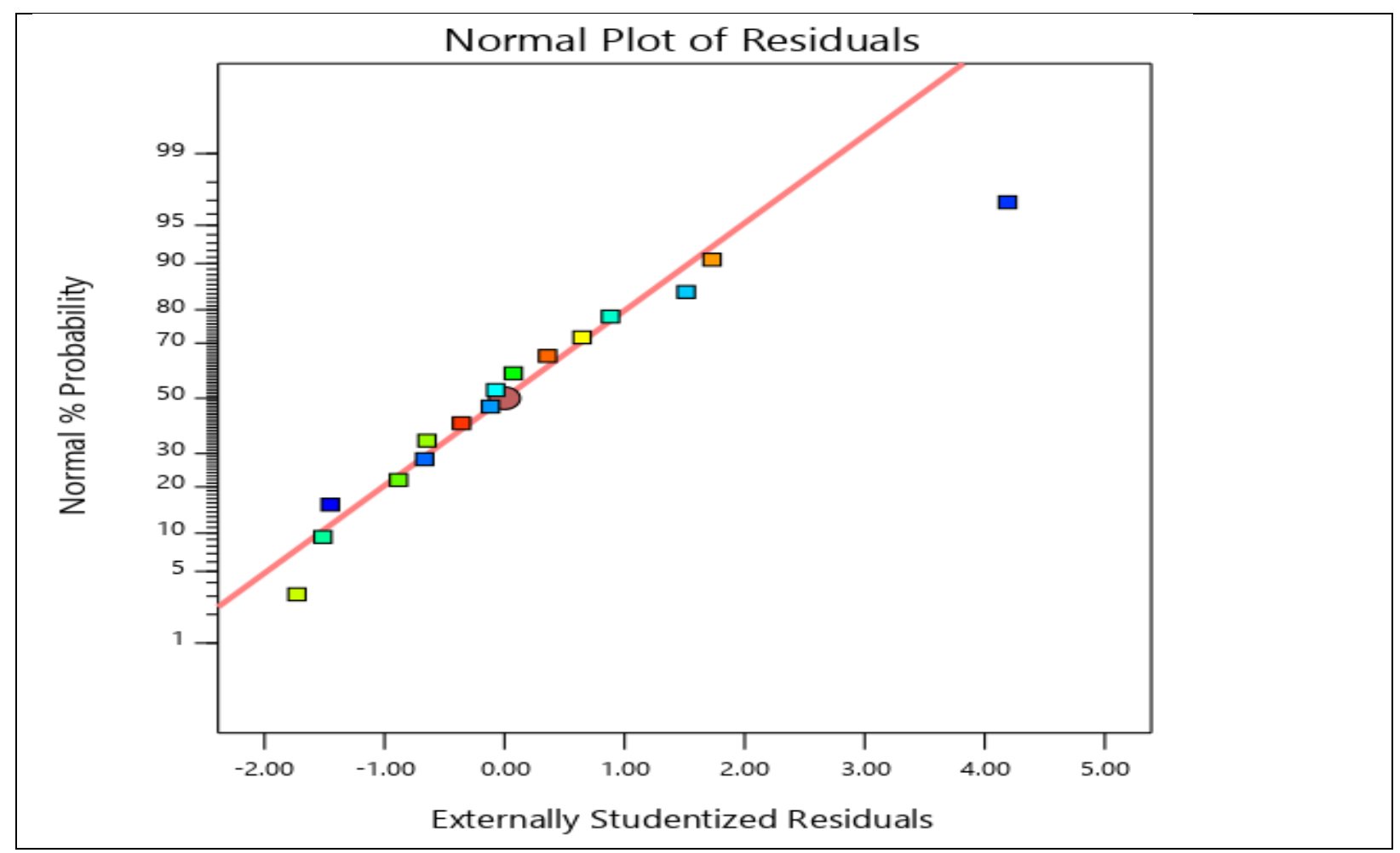

Figure 1: Normal probability plot of the residuals.

The purpose of a normality test is to determine whether experimental data constitute a normally distributed population (within some tolerance). This is essential because some tests including ANOVA require a normally distributed sample population otherwise if the assumption of normality is not valid, the results of the test will be unreliable.

In figure 1 , the set of data plotted graphically assume a normality pattern since they are clustered along the line of best fit. This portrays that the set is approximately normally distributed since departure from this trend line indicates departure from normality. The study concluded that residuals plot portrayed a normal trend.

\subsection{Model validation}

The graphical representation of predicted values obtained from the model under study with corresponding actual experimental response values is as shown in figure 5 . 


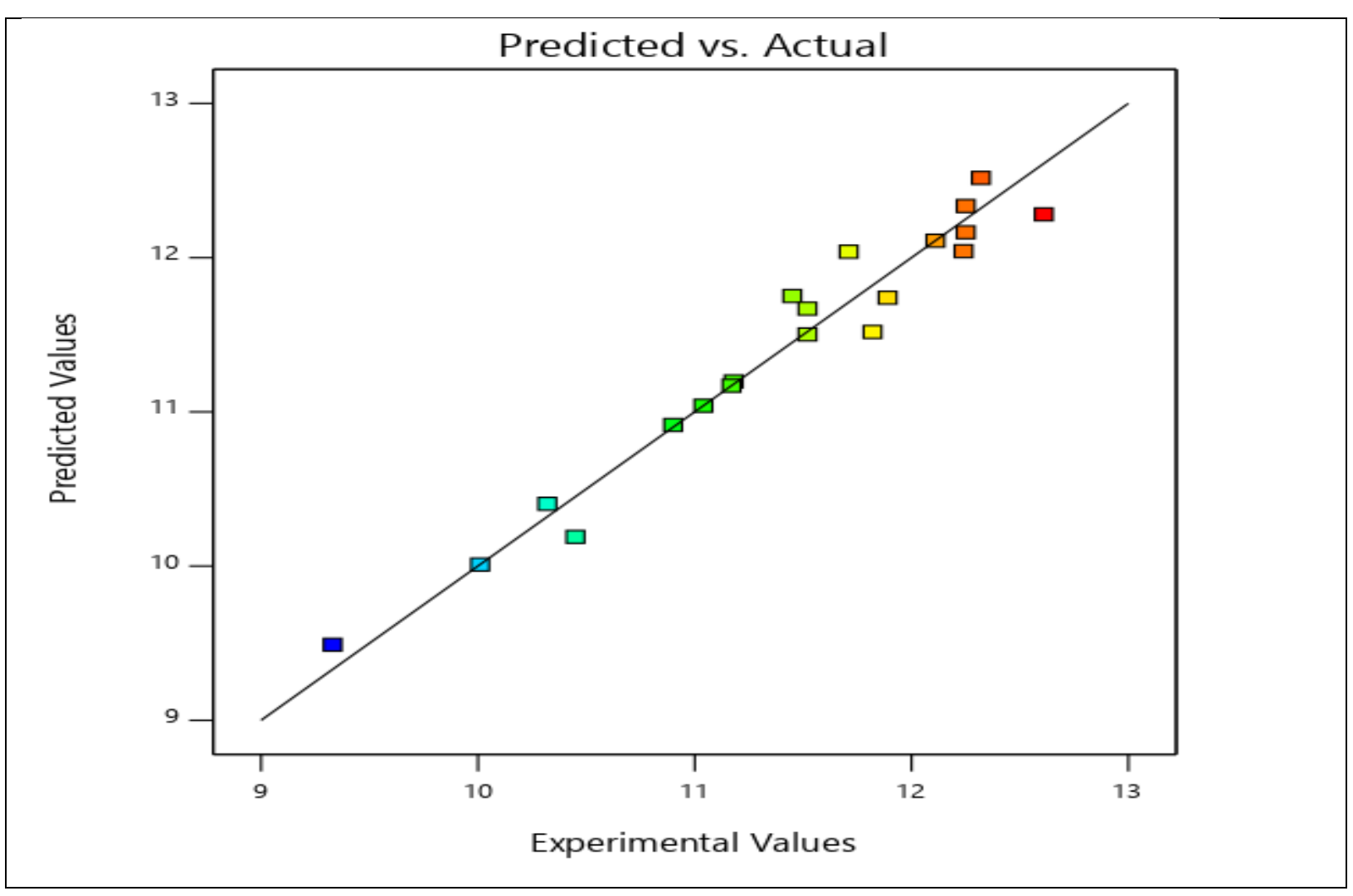

Figure 2: The Predicted values versus experimental values for maize Fodder

The plot provides a line of the best fit for predicted values versus the actual experimental values. Considering the line of best fit as a reference line, it was noted that each of the experimental values has shown closeness to this line of best fit. This close correlation between the predicted value and the actual value depicts the accuracy (fitness) of the model. In this study, the good correspondence in the comparison between both values was a clear indication that the third order mixture model could be used to describe the relationship between the factors and the response variable (Maize fodder).

\subsection{Determination of the optimal conditions for maize fodder production.}

The objective was to determine the optimal fertilizer components for optimal maize fodder production. The plotting of the 3D graphs by use of the model for the response variable maize fodder (Y) was found to be essential for the identification of the required optimal conditions. The 3D graphs were used in the study of the effects of any two or three component proportions by studying the response surface. The graphs were drawn by having one factor set at zero in turns. 


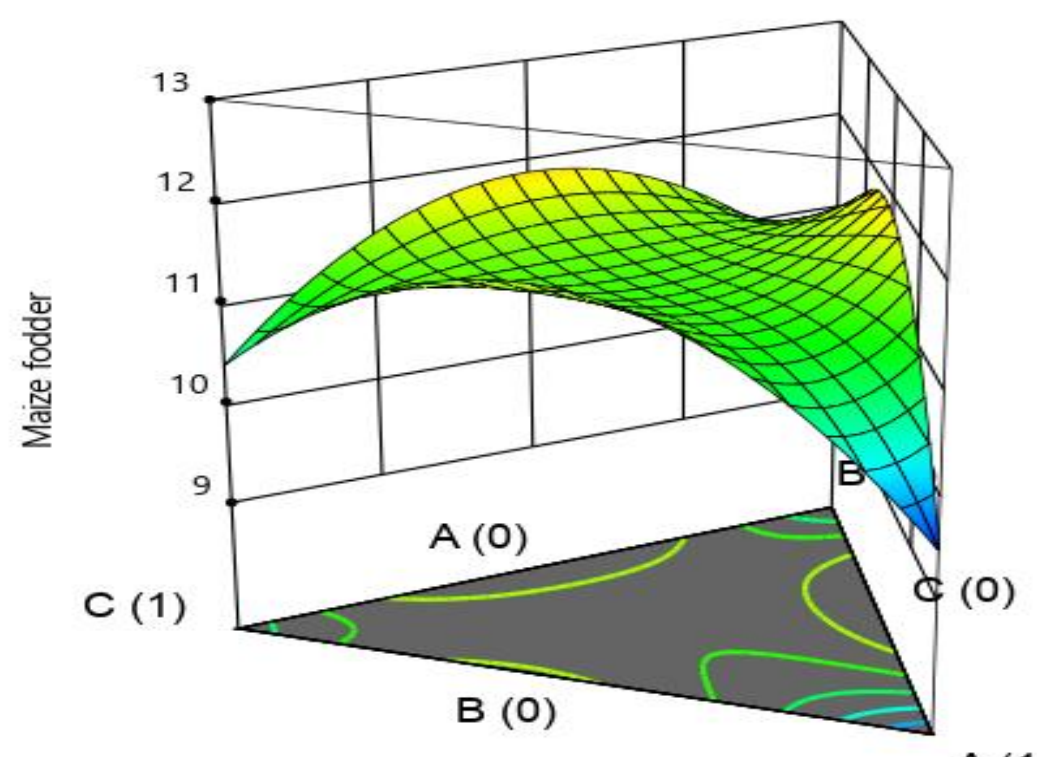

A (1)

Figure 3 Response surface for maize fodder as a function of farmyard manure (A), DAP (B) and sheep manure (C) at fixed Poultry manure (D) at zero.

Figure 3, shows the amount of maize fodder as a function of farmyard manure, DAP and sheep manure. It was observed that there was a significant increase in fodder from three different binary blends as displayed along the surfaces of the prism by crest on the curves. Therefore, the maximum fodder production was realized at two sets of points given by a blend of farmyard and DAP and the other set is DAP and sheep both blends having mixture components at $0.5,0.5$. In this case, the maximum predicted maize yield in terms of coded variables is $Y=11.87$ at Farmyard $\left(\mathrm{X}_{1}\right)=0.5$, DAP $\left(\mathrm{X}_{2}\right)=0.5$ and Sheep manure $\left(\mathrm{X}_{3}\right)=0$ or Farmyard manure $\left(\mathrm{X}_{1}\right)=0$, DAP $\left(\mathrm{X}_{2}\right)=0.5$ and Sheep manure $\left(\mathrm{X}_{3}\right)=0.5$ when Poultry manure $\left(\mathrm{X}_{4}\right)$ was set at zero. 


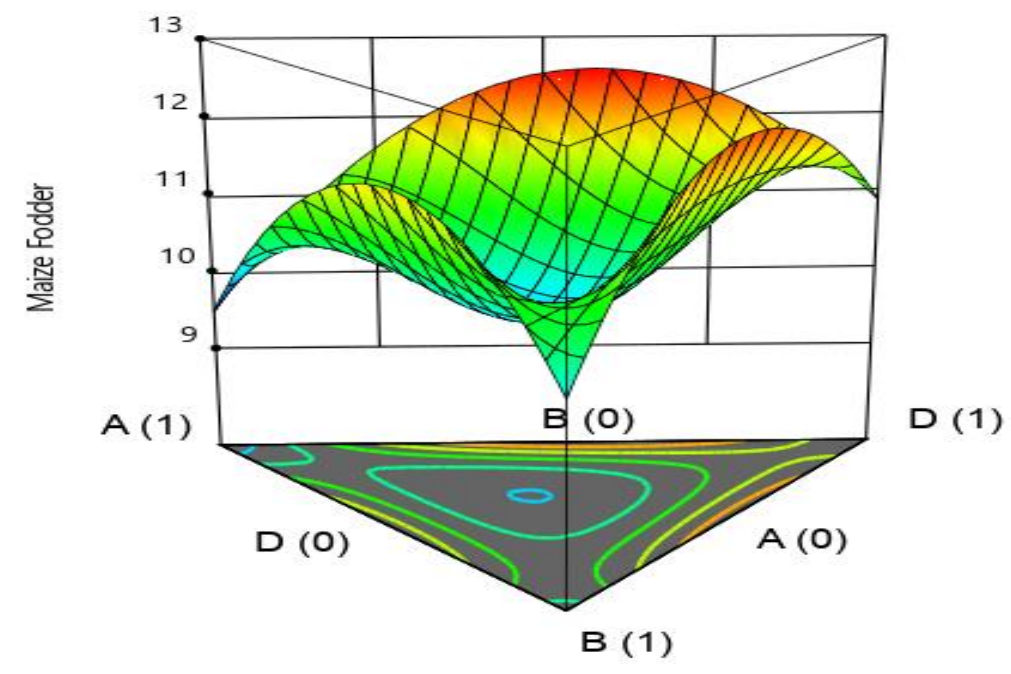

Figure 4: Response surface for maize fodder as a function of farmyard manure (A), DAP (B) and poultry manure $(C)$ at fixed sheep manure (D) at zero.

The optimal set of blend for maximum fodder production from the three components was exhibited by farmyard manure and poultry manure at coded values 0.4 and0.6 respectively. The study found that the maximum predicted maize fodder $(\mathrm{Y})=12.6$ under these set of coded variables; Farmyard manure $\left(\mathrm{X}_{1}\right)=0.4, \operatorname{DAP}\left(\mathrm{X}_{2}\right)=0$, Sheep manure $\left(\mathrm{X}_{3}\right)=0$ and Poultry manure $\left(\mathrm{X}_{4}\right)=0.6$. 


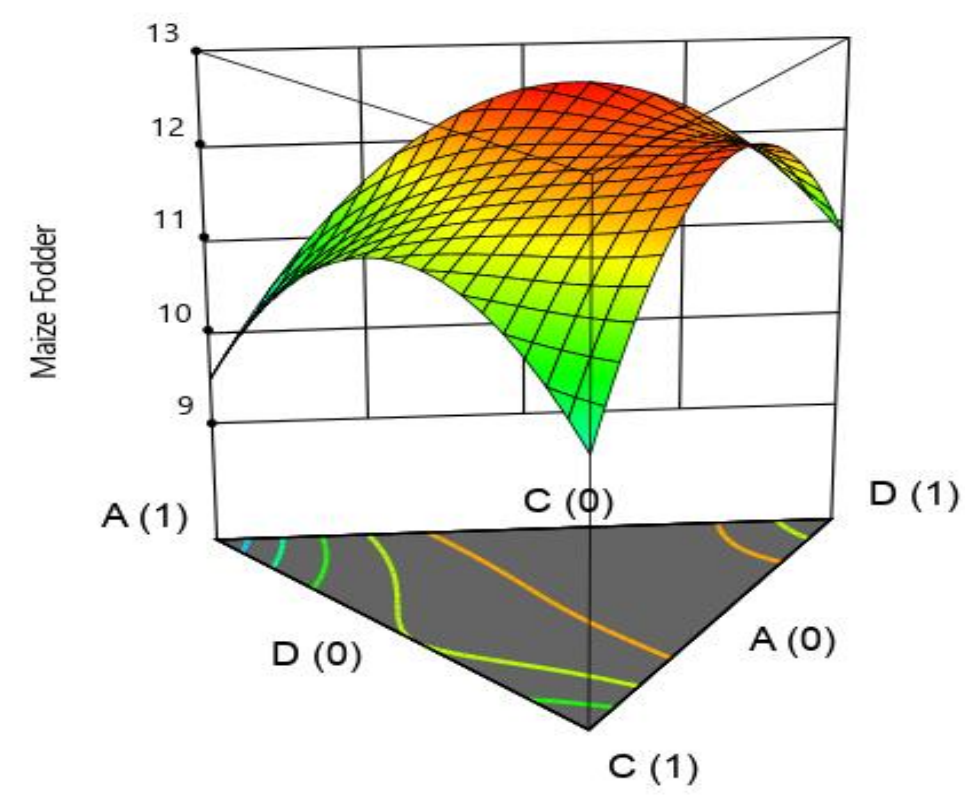

Figure 5: Response surface for maize fodder as a function of farmyard manure (A), sheep manure (C) and poultry manure (D) at fixed DAP (B) at zero.

The figure, show the amount of maize fodder as a function of farmyard manure, sheep manure and poultry manure. Again from the investigation of effect of the three components on the maize fodder production a mixture of farmyard manure and poultry manure produced the highest amount of fodder as indicated in the plot. The current analysis confirmed that the maximum predicted maize fodder $(\mathrm{Y})=12.6$ under the set of conditions in terms of coded variables; farmyard manure $\left(X_{1}\right)=0.4$, DAP $\left(X_{2}\right)=0$, Sheep manure $\left(X_{3}\right)=0$ and Poultry manure $\left(\mathrm{X}_{4}\right)=0.6$. 


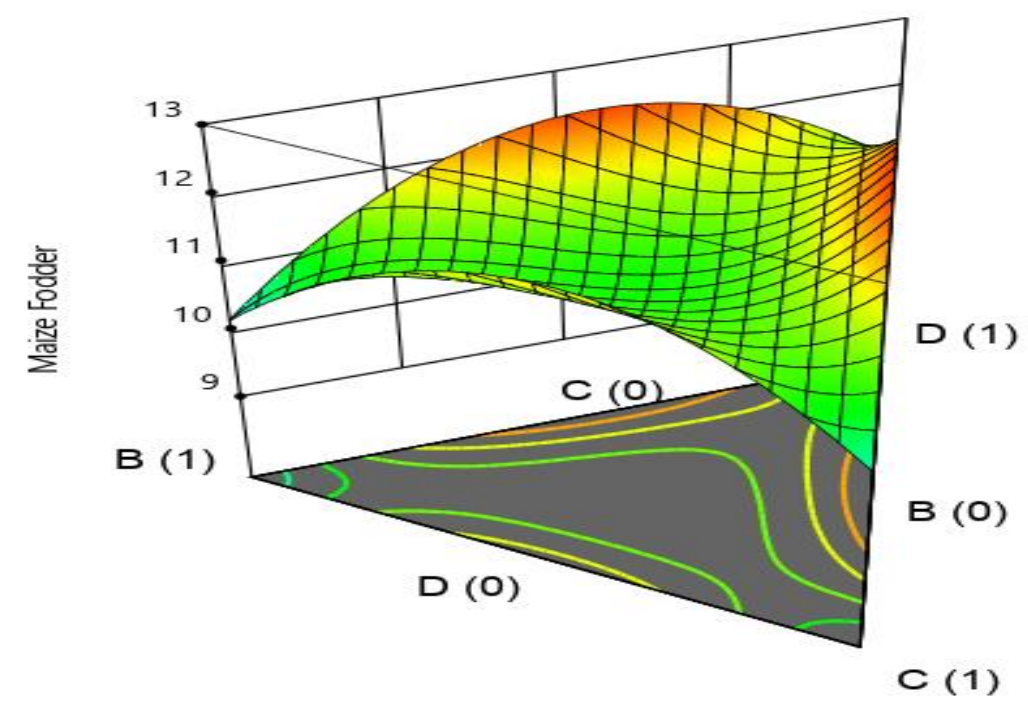

Figure 6: Response surface for maize fodder as a function of DAP (B), sheep manure and poultry manure at fixed farmyard manure (A) at zero.

From the plot, two sets of points stood out clearly featuring the maximum amount of maize fodder production. These are sets of DAP- poultry manure blend and sheep manure - poultry manure blend. The study found that the maximum predicted maize fodder $(\mathrm{Y})=12.6$ under the set of conditions in terms of coded variables.Farmyard manure $\left(X_{1}\right)=0, \operatorname{DAP}\left(X_{2}\right)=0.4$, Sheep manure $\left(X_{3}\right)=0$ and Poultry $\left(X_{4}\right)=0.6$.

\subsubsection{Summary for optimal conditions.}

From the four sets of analysis, and aided by graphical reprentation and contour navigation, the study concluded that the optimal set of points or component proportions is farmyard manure at 0.4 and poulty manure at 0.6 coded variables corresponding to an optimal maize fodder of $\mathbf{1 2 . 6} \mathbf{~ k g s}$. This translates to optimal maize fodder of 42.0 tons per hectare.

The objective of the study was to determine the optimal set of the fertilizer components proportion that produces maximum maize fodder. Hence, the desired conditions were given as tabulated below.

Table 7: Summary table for optimal conditions for maximum Maize fodder

\begin{tabular}{llll}
\hline Variables & Components & Optimal Value/coded & Actual Value/ ha \\
\hline $\mathbf{X}_{\mathbf{1}}$ & Farmyard & 0.4 & 8.0 tons \\
$\mathbf{X}_{\mathbf{2}}$ & DAP & 0 & 0 \\
$\mathbf{X}_{\mathbf{3}}$ & Sheep & 0 & 0 \\
$\mathbf{X}_{\mathbf{4}}$ & Poultry & 0.6 & 1.20 tons \\
$\mathbf{Y}$ & Maize Fodder & 12.6 & 42.0 tons \\
\hline
\end{tabular}




\subsection{Conclusion}

Mixture experiments involve combining two or more components in various proportions with a view of collecting data on one or more response(s) of interest. For instance, the growth of maize plants depends on a number of nutrients from soil or supplied during planting as fertilizer. Mixture experiments are therefore suitable to use when investigating if synergism exist in various blends of these fertilizer components. A four- fertilizer component design used in this study illustrates how mixture experiments can be applied in agricultural research. However, the statistical model demonstrates the effects of single, binary and tertiary components on the response variable of interest. Hence, the study concluded that the models could be used to predict the production that could be realized from any mixture proportion. Further, the study found that there was a synergetic effect in six binary blends but more conspicuous on farmyard manure and poultry manure. Nevertheless, an optimal set of conditions was obtained from a blend of 8.0 tons/Ha of farmyard manure and $\mathbf{1 . 2 1 2}$ tons/Ha of poultry manure with an optimal maize fodder of $\mathbf{4 2 . 0}$ tons/ Ha. The study exemplified that the development of statistical models for crop production can be useful for prediction and understanding the effects of experimental factors (Muriithi 2019).

\subsection{ACKNOWLEDGEDMENT}

The author is grateful with the support received from University of Kabianga research and teaching farm.

\subsection{REFERENCES:}

Awais Shakoor, Muhammad A., Shah 1., Asif A., Aaqil K., Alam s., Misbahullah, ad Kamran M.(June 2015). Impact of farmyard manure and Nitrogen Phosphorus and Potassium on maize crop. Academic Research Journal of Agriculture Science and research Vol3(8), 219-223.

Boateng S., A.J.Zickermann and M. Kornaharens (2006). Effect of Poultry Manure on growth and yield of maize. West Africa J.App. Eco. 9:1-11.

Cornell, J.A. (1990). Experiments with mixtures: Designs, Models, and the Analysis of Mixture Data. (Second edition).

Khuri, A. I and Cornell, J. A (1987). Response Surface: Design and Analyses, Marcel Dekker. New York, NY.prediction of compressive strength of sand Crete blocks using alluvial deposit. Nigerian Journal of technology Vol. 30(3).

Montgomery D.C. (2000), Design and analysis of experiments fifth edition. John Wiley and Sons New York. NY.

Muriithi. D. K (2019). Application of Simplex Lattice Design in Watermelon Production, Journal of Mathematical Theory and Modeling, Vol. 9, No. 1, pp. 104 111

Muriithi D. K. (2017). The optimization of multiple responses of water melon to organic manure using response surface methodology, European international Journal of science and technology 2017, Vol. 6(2):5270 .

Scheffe', H. (1958). Experiments with mixture. Journal of the Royal Statistical Society Series, B, 20, No.2, 344360 . 
Shiyam J.O., Garjila Y.A., and Bobboyl M. (2017), Effect of Poultry Manure on growth and Yieldof maize (Zea mays Var praecox) in Jalingo Taraba state, Nigeria. Journal of Applied life Sciences international 10(4):1-6, 2017 ; Article no. JALSI.31972. 